\title{
Discurso do Sujeito Coletivo: a visão dos docentes do curso de ciências biológicas licenciatura de uma Universidade Federal frente à inclusão de alunos com deficiência no Ensino Superior
}

\section{Collective Subject Speech: the view of teachers in the course of biological sciences degree from a federal university in view of the inclusion of students with disabilities in higher education}

iD João Paulo Xavier de Freitas Graduando em Ciências Biológicas Licenciatura pela Universidade Federal de Itajubá (2016). Foi bolsista Capes no Programa Institucional de Bolsas de Iniciação à Docência - PIBID (2014-2015). Desde 2018 é integrante do Núcleo de Estudos em Formação Docente, Tecnologias e Inclusão (NEFTI) e do Grupo de

Estudos Interdisciplinares e Formação de Professores (GEIFOP). Participou do Programa Residência Pedagógica e do Projeto de Extensão Práticas Inclusivas no Ensino de Ciências (2018-2019). Atuou como bolsista de iniciação científica no Núcleo de Educação Inclusiva (NEI) da Unifei (2019).

Universidade Federal de Itajubá Itajubá - Minas Gerais, Brasil. joaopaulopxf@gmail.com

Ana Carolina Sales Oliveira

É graduada em Fonoaudiologia pela Pontifícia Universidade Católica de Campinas (2005) e Pedagogia pela Universidade Paulista (2014). É especialista em Linguagem pela Faculdade de Ciências Medicas da

Santa Casa de São Paulo( FCMSCSP). É especialista em Informática em Educação pela Universidade Federal de Lavras (Ufla). É especialista em Língua Brasileira de Sinais (Libras) pela Faculdades Integradas de Jacarepaguá. É especialista em Audiologia pelo CEFAC Saúde e Educação. É especialista em Neuropsicopedagogia pelo Centro Universitário Leonardo Da Vinci. Mestra e Doutora em Ciências da Linguagem (CAPES 4) pela Universidade do Vale do Sapucaí. Professora da Disciplina de LIBRAS e Linguagem e Comunicação na Universidade Federal de Itajubá (Unifei). Universidade Federal de Itajubá Itajubá - Minas Gerais, Brasil. anacarolinasales@unifei.edu.br

Resumo: A inclusão de alunos com deficiência no Ensino Superior brasileiro é respaldada por aparatos legais criados ao longo dos últimos 30 anos. Apesar disso, nota-se grande dificuldade de as universidades lidarem de forma efetiva com esse público alvo. Desta forma, este trabalho tem por objetivo averiguar as percepções de docentes de uma universidade federal quanto à inclusão educacional destes alunos em um curso de licenciatura em ciências biológicas. Por meio do método do Discurso do Sujeito Coletivo, foi possível verificar e discutir os desafios que envolvem essa questão, identificando que, para além de políticas públicas, a prática docente adequada e a criação de ações pela universidade são essenciais para a real inclusão destes alunos.

Palavras-chave: Educação Inclusiva. Ensino Superior. Inclusão.

Abstract: The inclusion of students with disabilities in Brazilian higher education is supported by legal mechanisms created over the past 30 years. Therefore, there is a great difficulty for universities to deal effectively with this target audience. In this way, this work aims to investigate the perceptions of teachers at a Federal University, regarding the educational inclusion of these 
FREITAS, João Paulo Xavier de; OLIVEIRA, Ana Carolina Sales. Discurso do Sujeito Coletivo: a visão dos docentes do curso de ciências biológicas licenciatura de uma Universidade Federal frente à inclusão de alunos com deficiência no Ensino Superior

students in an Biological Sciences degree course. Through the Collective Subject Speech method, it was possible to verify and discuss the challenges surrounding this issue, identifying that in addition to public policies, adequate teaching practice and the creation of actions by the university that are essential for the real inclusion of these students.

Key-words: Inclusive Education. University Education. Inclusion.

\section{Introdução}

O ingresso e a participação de alunos com deficiência em Instituições de Ensino Superior ocorreram de forma gradativa e recente no Brasil. A publicação da Constituição Federal de 1988 (BRASIL, 1988) foi o marco inicial para mudanças no sistema educacional do país, tendo como prioridade o acesso universal à educação. Mas, de fato, as mudanças relativas à inclusão começaram a acontecer na década de 90, influenciadas por debates em eventos internacionais e acordos entre diversos países.

A Conferência Mundial sobre Educação para Todos, que aconteceu na Tailândia em 1990 e que foi promovida pela Organização das Nações Unidas para a Educação, Ciência e Cultura (UNESCO), pelo Fundo das Nações Unidas para a Infância (UNICEF), pelo Programa das Nações Unidas para o Desenvolvimento (PNUD) e pelo Banco Mundial, foi primordial para mudanças significativas. A conferência proclamou a Declaração Mundial sobre Educação para Todos (UNESCO, 1990), que evidenciou a importância de universalizar o acesso à educação e promover a equidade entre os estudantes. $\mathrm{O}$ documento ainda evidencia a necessidade de criar medidas que garantam a igualdade de acesso aos alunos com deficiências.

Outro evento importante foi a Conferência Mundial sobre Necessidades Educativas Especiais que ocorreu em 1994, na Espanha, também organizada pela UNESCO. Por meio dela foi elaborada a Declaração de Salamanca (BRASIL, 1994), documento importante que consolidou a educação inclusiva no cenário mundial e que teve como base o resgate dos pontos estabelecidos na Declaração dos Direitos Humanos. Ela foi responsável por colocar os alunos com deficiência legitimamente como parte do sistema educacional, incentivando modificações no cenário escolar para que todos os estudantes aprendessem juntos de maneira a proporcionar uma sala de aula realmente inclusiva.

Até esta década, a Educação Especial, que era vista como complementar a todos os âmbitos educacionais, passa a ganhar uma perspectiva inclusiva, em que o ambiente escolar deveria se adaptar aos alunos com deficiência sem que houvesse quaisquer tentativas de normalização destes estudantes. Sob a influência destes documentos e com base na nova constituição, foi criada, em 1996, a nova Lei de Diretrizes e Bases para a Educação Nacional (BRASIL, 1996), afirmando 


\section{Dialogia}

FREITAS, João Paulo Xavier de; OLIVEIRA, Ana Carolina Sales. Discurso do Sujeito Coletivo: a visão dos docentes do curso de ciências biológicas licenciatura de uma Universidade Federal frente à inclusão de alunos com deficiência no Ensino Superior

o direito ao acesso destes alunos à educação de qualidade, de modo a ser oferecida prioritariamente na rede regular de ensino, com direito ao atendimento educacional especializado (AEE).

Ainda em 1996, foi emitido o Aviso Circular n² 277 MEC/GM8 (BRASIL, 1996) dirigido aos Reitores das Instituições de Ensino Superior para que exerçam uma política educacional adequada no que tange à inclusão de alunos com deficiências. Este documento sugere que os mecanismos de ingresso sejam readequados, reestruturando os editais e o modo de aplicação dos vestibulares. Além disso, coloca-se em pauta a importância da flexibilização dos meios acadêmicos e da reestruturação dos recursos físicos e de pessoal das universidades.

Em 1999, é deferida a Portaria n. ${ }^{\circ}$ 1.679/99 (BRASIL, 1999), que dispõe sobre a importância de assegurar recursos para promover a acessibilidade de alunos com deficiências físicas e/ou sensoriais, além de determinar o credenciamento de instituições que estejam devidamente preparadas para receber esse público. Ainda nesse ano, foi aprovado o Decreto no 3.298/99 determinando no artigo 27 que:

as instituições de ensino superior deverão oferecer adaptações de provas e os apoios necessários, previamente solicitados pelo aluno [...], inclusive tempo adicional para a realização das provas, conforme as características da deficiência. (BRASIL, 1999)

O texto ainda sugere a introdução nos currículos dos programas de educação superior conteúdos, itens ou disciplinas relacionados à pessoa com deficiência. A década se encerra legalmente respaldada, entretanto, os dados censitários educacionais ainda não faziam referência à entrada de alunos com deficiências nas universidades, sendo apresentados a partir do ano de 2000 (CABRAL, 2017). Desta forma, não é possível observar o impacto causado pelas mudanças nessa década.

Ao iniciar o novo século, importantes mudanças aconteceram a fim de promover melhorias no âmbito educacional. No ano de 2001, o Conselho Nacional de Educação (CNE) instituiu a resolução que designou as Diretrizes Nacionais para a Educação Especial na Educação Básica (BRASIL, 2001). Estas Diretrizes determinaram o atendimento educacional especializado aos alunos com deficiência na rede pública de ensino desde a educação infantil ao ensino superior. Além disso, asseguraram a acessibilidade e a flexibilização dos sistemas de ensino para que a inclusão ocorresse de maneira efetiva.

Em 2002, a Língua Brasileira de Sinais (Libras) teve seu reconhecimento como língua oficial no Brasil, por meio da Lei 10.436/2002 e foi regulamentada oficialmente por intermédio do Decreto Federal 5.626/05 (BRASIL, 2005), que assegurou o ensino de Libras em todo o processo educacional. Assim, as pessoas com deficiência auditiva adquiriram o direito de serem educadas em 
FREITAS, João Paulo Xavier de; OLIVEIRA, Ana Carolina Sales. Discurso do Sujeito Coletivo: a visão dos docentes do curso de ciências biológicas licenciatura de uma Universidade Federal frente à inclusão de alunos com deficiência no Ensino Superior

Libras como primeira língua e pela Língua Portuguesa na modalidade escrita, como segunda língua, o que corroborou mudanças em todo o cenário acadêmico. Ainda, por meio deste Decreto, a disciplina de LIBRAS foi obrigatoriamente incorporada aos currículos dos cursos de formação de professores e de fonoaudiologia e, de forma optativa, nos demais cursos de graduação (BRASIL, 2005).

Ainda nessa década é lançado um dos mais importantes programas que promoveu o acesso desses estudantes no ensino superior, o Incluir, instituído pelo Ministério da Educação no ano de 2005. A partir do ano de 2007, esse mesmo programa garantiu o fortalecimento e criação de Núcleos de Acessibilidade nas universidades públicas, responsáveis por dar suporte à permanência dos alunos com deficiências (MOREIRA; BOLSANELLO; SEGER, 2011).

Em 2008, o Ministério da Educação institui a "Política Nacional de Educação Especial na Perspectiva da Educação Inclusiva" (BRASIL, 2008), com diretrizes que apontam para a transversalidade da educação especial no ensino superior. Ela garante o planejamento e organização de recursos para promover o acesso, a participação e a aprendizagem desses alunos, visando promover soluções às necessidades educacionais apresentadas.

O Estatuto da Pessoa com Deficiência foi criado no ano de 2015 por meio da edição da Lei $\mathrm{n}^{\circ}$ 13.146/2015 (BRASIL, 2015) com o objetivo de assegurar os direitos fundamentais das pessoas com deficiências. No Artigo 27, é colocado como direito o acesso ao sistema educacional em todos os níveis de escolarização promovendo o desenvolvimento das habilidades desse público. Além disso, é válido ressaltar, o Artigo 28 que, entre outros apontamentos, coloca que é incumbência do poder público desenvolver um

projeto pedagógico que institucionalize o atendimento educacional especializado, assim como os demais serviços e adaptações razoáveis, para atender as características dos estudantes com deficiência e garantir seu pleno acesso ao currículo em condições de igualdade, promovendo a conquista e o exercício de sua autonomia. (BRASIL, 2015).

Mesmo com tantos aparatos legais criados no período histórico mencionado acima, ainda se nota grande dificuldade de as universidades lidarem com este público alvo. Desta forma, este trabalho consiste em averiguar as percepções de docentes de uma universidade federal quanto à inclusão educacional desses alunos em um curso de licenciatura em ciências biológicas. De modo a identificar e discutir os desafios que envolvem esta questão e o papel do professor mediante o contexto da inclusão dos alunos com deficiência no curso. 


\section{Dialogia}

FREITAS, João Paulo Xavier de; OLIVEIRA, Ana Carolina Sales. Discurso do Sujeito Coletivo: a visão dos docentes do curso de ciências biológicas licenciatura de uma Universidade Federal frente à inclusão de alunos com deficiência no Ensino Superior

\section{Metodologia}

Para a realização desta pesquisa foi utilizada a técnica do Discurso do Sujeito Coletivo DSC, desenvolvida por Lefevre e Lefevre no fim da década de 90. Essa metodologia é uma alternativa para a representação das opiniões obtidas por meio de pesquisas empíricas, que, geralmente, são veiculadas por meio do meta discurso do pesquisador ou organizadas a partir de ferramentas matemáticas (Lefevre, Lefevre, 2006). Assim, a partir desta proposta pode-se obter representações sociais sem perder o caráter discursivo das opiniões coletadas e sem reduzi-las a quantidades.

Os procedimentos sistemáticos estabelecidos pelos seus criadores permitem a análise do conteúdo obtido em pesquisas que utilizam questões abertas para a coleta de dados. Todas as perguntas devem ser criadas estrategicamente para que seja possível obter respostas que articulem as mais variadas representações sociais envolvidas (FIGUEIREDO; CHIARI; GOULART, 2013). Desta forma, a partir dos procedimentos é possível obter depoimentos coletivos que são constituídos por fragmentos das respostas obtidas individualmente.

A partir de cada uma das respostas coletadas, o pesquisador deve selecionar as expressõeschave constituídas pelos trechos mais importantes relacionados à questão proposta. Por meio delas é possível destacar as Ideias Centrais que resumem o conteúdo discursivo manifestado em cada uma das expressões. Para que sejam elaborados os depoimentos coletivos, sintetizando todos os discursos obtidos na pergunta, são agrupadas todas as expressões-chave que correspondem a uma mesma categoria e com a mesma ideia-central. Assim, é possível construir um DSC tendo como estrutura um texto na primeira pessoa do singular.

Ao procurar apoio na estrutura da língua portuguesa, nota-se que o pronome "nós" pode ser uma possibilidade para representar a existência de um sujeito coletivo. Entretanto, ao utilizá-lo, a representação dá-se de forma ineficiente, uma vez que expressa apenas um tipo muito particular de sujeito coletivo que fala. Segundo Lefevre e Lefevre (2014, p. 504)

tais histórias coletivas refletem ou carregam códigos narrativos socialmente compartilhados; por isso, é possível com os conteúdos e os argumentos dos diferentes depoimentos que apresentam sentido semelhante, construir, na primeira pessoa do singular, uma narrativa verossímil, ou seja, uma história aceitável para um indivíduo. (LEFEVRE, LEFEVRE, 2014, p. 504).

Os DSC resultantes da pesquisa se tornam, então, um produto científico tratado pelo pesquisador, mas que conserva as características espontâneas da fala e que representa o pensamento coletivo do grupo estudado. Para construir os DSC, foi utilizado o DSCSoft, um software disponibilizado pelos autores da metodologia para facilitar a coleta e organização dos dados. Ele 
FREITAS, João Paulo Xavier de; OLIVEIRA, Ana Carolina Sales. Discurso do Sujeito Coletivo: a visão dos docentes do curso de ciências biológicas licenciatura de uma Universidade Federal frente à inclusão de alunos com deficiência no Ensino Superior

permite com que os processos mecânicos e os procedimentos de análise sejam agilizados, concentrando o pesquisador nas etapas que exigem abstração e habilidade intelectual. Além disso, ele organiza os dados em gráficos que representam a frequência das opiniões em relação a diferentes variáveis, como a idade dos entrevistados, formação acadêmica e sexo.

Dessa forma, nota-se que os DSC permitem entender a problemática estudada tanto de forma qualitativa, entendendo o caráter do pensamento coletivo, quanto quantitativa, compreendendo as relações com base na quantidade e frequência das opiniões. A pesquisa ainda se caracteriza como um estudo de caso, visto que busca compreender as percepções dos professores de um curso e de uma universidade específica.

Os sujeitos da pesquisa foram constituídos pelos docentes que atuam nas disciplinas específicas de biologia e nas disciplinas de prática de ensino e estágio supervisionado do curso de Ciências Biológicas Licenciatura de uma universidade federal. Foram elaboradas perguntas abertas envolvendo as possíveis percepções dos professores relacionadas ao ingresso de alunos com deficiência no curso e o posicionamento dos docentes frente a situações-problema decorrentes desta possibilidade.

\section{Resultados e Discussões}

Dentre os oito professores entrevistados, três cursaram apenas o curso de ciências biológicas bacharelado e cinco cursaram ciências biológicas licenciatura, tendo, entre eles, um licenciado em pedagogia. Em relação à formação continuada, dois apresentam mestrado e doutorado em Educação e os demais nas áreas específicas de biologia. O tempo de docência na instituição referida varia de um a seis anos, ministrando aulas no curso de ciências biológicas licenciatura e em outros cursos da universidade. Os dois docentes doutores em educação ministram as práticas de ensino e as disciplinas de estágio supervisionado, enquanto o restante leciona as disciplinas de biologia conforme áreas de enfoque.

A primeira pergunta apresentada questionou os docentes a respeito do contato com a temática inclusiva durante a formação inicial e continuada. Como é possível observar no gráfico 1 , a maior parte (cinco docentes) não teve nenhum contato com a temática e apenas dois relataram o contato durante as disciplinas pedagógicas de seus cursos de licenciatura. Além disso, um professor relatou que a aproximação com o tema se deu de forma indireta, por meio de eventos e palestras. 


\section{Dialogia}

FREITAS, João Paulo Xavier de; OLIVEIRA, Ana Carolina Sales. Discurso do Sujeito Coletivo: a visão dos docentes do curso de ciências biológicas licenciatura de uma Universidade Federal frente à inclusão de alunos com deficiência no Ensino Superior

Gráfico 1 - Respostas da pergunta: Ao longo de sua formação você teve contato com a temática inclusiva?

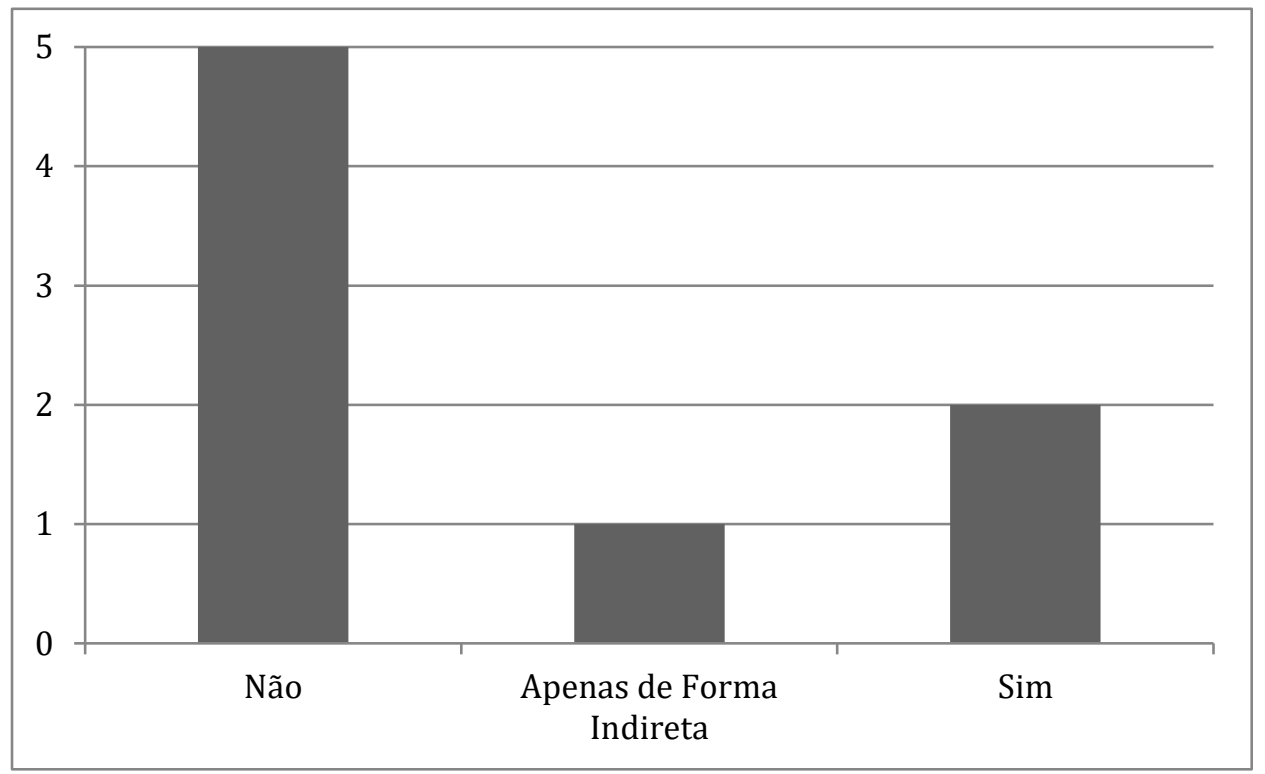

Fonte: Os autores (2019).

Diante dos dados coletados, é interessante destacar que, mesmo com os aparatos legais criados nos anos 90, a maior parte dos professores não teve contato com a temática inclusiva em sua formação acadêmica, o que demonstra a demora de adaptação por parte das universidades em (re)adequar seu currículo acadêmico. Esse problema acarreta sérias consequências no que concerne à inclusão desses alunos em sala de aula, gerando custos e dificuldades que poderiam ser evitadas (SANT'ANA, 2005). Dessa forma, é válido ressaltar que formação docente não pode se restringir a eventos pontuais, mas deve ser realizada de maneira integrada e permanente.

\section{A inclusão de alunos com deficiência no ensino superior}

Com o objetivo de detectar as percepções dos professores a respeito da entrada de alunos com deficiência no Ensino Superior, foram realizadas duas perguntas. A seguir, identificam-se os discursos do sujeito coletivo em resposta à questão norteadora: o que você pensa sobre a inclusão de alunos com deficiência (física, sensorial ou intelectual) no Ensino Superior? Foram estabelecidas duas categorias, representando os diferentes discursos. Na tabela 1 pode-se observar o DSC da categoria A. 
FREITAS, João Paulo Xavier de; OLIVEIRA, Ana Carolina Sales. Discurso do Sujeito Coletivo: a visão dos docentes do curso de ciências biológicas licenciatura de uma Universidade Federal frente à inclusão de alunos com deficiência no Ensino Superior

Tabela 1 - Categoria A: a Universidade deve estar preparada para receber alunos com deficiência

\begin{tabular}{|l|l|}
\hline \multicolumn{1}{|c|}{ DSC } & \multicolumn{1}{|c|}{ Frequência } \\
\hline Importante, porém, deve ser sempre pensada de forma que o suporte a ser dado ao & $50 \%$ das respostas \\
aluno esteja institucionalizado antes do seu ingresso. As atividades de inclusão & compõem este DSC. \\
podem auxiliar o desenvolvimento pessoal dos individuos com determinada & \\
deficiência, porém, o sucesso destas atividades está atrelado ao nivel de preparação & \\
da Universidade. O Ensino Superior precisa se adequar em diversos sentidos para & \\
que possa valorizar os estudantes com deficiência e conseguir proporcionar a eles uma & \\
formação humana de qualidade. & \\
\hline
\end{tabular}

Fonte: Os autores (2019).

O DSC dos professores nessa categoria apontou para a necessidade de as Instituições de Ensino Superior estarem preparadas para receber os alunos com deficiências antes de seu ingresso. Entretanto, é preciso levar em consideração que as universidades públicas não podem ser responsabilizadas integralmente por esse processo de adequação. São necessárias medidas que vão além do poderio das instituições, como a destinação de recursos para o financiamento adequado de recursos físicos e humanos que facilitem o acesso e permanência desses estudantes.

É válido ressaltar que apenas a disponibilidade de recursos e o amparo legal não são suficientes para promover práticas inclusivas. A constituição de uma educação inclusiva reivindica uma reestruturação dos sistemas de ensino que amparem as necessidades educacionais de todos os estudantes (ROCHA; MIRANDA, 2009). Assim, as universidades devem repensar seus modelos educacionais e organizar ações práticas que atendam à diversidade de alunos, propondo, por exemplo, uma flexibilização do currículo acadêmico, pensando em formas alternativas de avaliação e adequação das atividades relacionadas à pesquisa e extensão. Abaixo, na Tabela 2, verifica-se o DSC da categoria B.

Tabela 2 - Categoria B: os Docentes devem estar preparados para receber alunos com deficiências

\begin{tabular}{|l|l|}
\hline DSC & \multicolumn{1}{|c|}{ Frequência } \\
\hline Considero um grande avanço para a sociedade brasileira e importante para a & $50 \%$ das respostas \\
formação de uma sociedade justa. Contudo, os profissionais precisam de treinamento & compõem este DSC. \\
adequado. Entendo que tais estudantes têm direito a uma educação de qualidade, & \\
mas, muitas vez̧es, os professores não conseguem dar conta dessa demanda. Apesar & \\
da nossa legislação incluir pessoas com deficiência nas universidades, ainda são & \\
poucas as que ingressam e concluem o ensino superior. Isso devido a vários fatores, & \\
como falta de formação pedagógica de docentes para educação inclusiva. & \\
\hline
\end{tabular}

Fonte: Os autores (2019). 


\section{Dialogia}

FREITAS, João Paulo Xavier de; OLIVEIRA, Ana Carolina Sales. Discurso do Sujeito Coletivo: a visão dos docentes do curso de ciências biológicas licenciatura de uma Universidade Federal frente à inclusão de alunos com deficiência no Ensino Superior

Os apontamentos neste DSC denotam a importância da preparação dos professores frente à entrada de alunos com deficiências na universidade. A constituição de um professor preparado para a educação inclusiva deve começar durante a formação inicial docente. Assim, no ano de 2002 houve a publicação das Diretrizes Curriculares Nacionais para a Formação de Professores da Educação Básica - Resolução CNE/CEB n. 1/02 (BRASIL, 2002), que levam as instituições de ensino superior a contemplar os aspectos relacionados à inclusão e especificidades dos alunos com deficiência nos cursos de licenciatura.

Apesar desse avanço, muitas instituições ainda não implementaram ações efetivas que possibilitem a formação docente voltada para a proposta inclusiva. A falta de professores formadores especializados e a abordagem reduzida nos cursos de licenciatura corroboram uma formação voltada à inclusão insuficiente. Assim, para além da inserção reduzida do conteúdo, é necessário que a formação docente esteja atrelada a uma reflexão constante sobre as atitudes do futuro professor frente às diferenças encontradas em sala de aula (FERRARI; SEKKEL, 2007). Tal reflexão é tão importante e necessária quanto o domínio dos conhecimentos específicos.

Além disso, muitos professores que atuam nas universidades não se graduaram em licenciatura e, por isso, não tiveram nenhum tipo de contato com a temática durante a formação inicial. Dessa forma, destaca-se a importância da formação continuada para que o professor permaneça constantemente atualizado para atender as demandas de seus alunos. A universidade também deve fornecer subsídios para que seus docentes estejam preparados para lidar com uma proposta educacional voltada à inclusão, possibilitando o contato dos professores com profissionais da área e colocando em pauta a discussão desse assunto no âmbito acadêmico.

No caso dos entrevistados, foi possível perceber, inicialmente, que, mesmo com a maioria dos docentes sendo graduados em licenciatura, só uma minoria teve acesso a uma formação atrelada à inclusão educacional. Os professores concluíram a formação inicial no intervalo entre 1999 e 2011 e, nesse tempo, já haviam sido publicadas leis e diretrizes que regulamentam a introdução da temática inclusiva nos cursos de licenciatura. Dessa forma, nota-se que as universidades ainda estão se adequando a essas questões e muitas delas ainda não conseguem formar professores preparados para lidar com alunos com deficiências em sala de aula.

Ainda sobre a temática "inclusão de alunos com deficiência no ensino superior" foi realizada uma segunda pergunta: "na sua opinião, a universidade deve receber e apoiar todos os alunos sem distinção? " Abaixo, estão os discursos do sujeito coletivo referentes às duas categorias estabelecidas. Na tabela 3 pode-se observar o DSC referente à primeira categoria. 
FREITAS, João Paulo Xavier de; OLIVEIRA, Ana Carolina Sales. Discurso do Sujeito Coletivo: a visão dos docentes do curso de ciências biológicas licenciatura de uma Universidade Federal frente à inclusão de alunos com deficiência no Ensino Superior

Tabela 3 - Categoria A: a Universidade é um direito de todos

\begin{tabular}{|l|l|}
\hline DSC & \multicolumn{1}{|c|}{ Frequência } \\
\hline A universidade deve ser um ambiente que agregue a todos sem & $62,5 \%$ das respostas \\
discriminação. Ela é um direito de todas as pessoas que nela querem estar. & compõem este DSC. \\
Uma vezque a Universidade visa à formação e desenvolvimento pessoal dos & \\
alunos que a frequentam, a inclusão de indivíduos especiais é uma de suas & \\
obrigações. A inclusão é um processo para além do respeito, precisa se dar & \\
no sentido da valorização de todos os estudantes sem distinção e a & \\
universidade, enquanto instituição social tem papel fundamental nisso. & \\
\hline
\end{tabular}

Fonte: Os autores (2019).

Ficou em evidência nesse DSC a percepção de que a universidade deve ser um local de valorização de todas as pessoas que querem frequentá-la, sem quaisquer distinções. A sociedade é constituída de forma dinâmica e integrada, considerando todas as partes que possuem diferenças e individualidades. Dessa forma, a pessoa com deficiência passa a ser incluída quando é olhada nesse contexto totalizador, de forma a conseguir se conectar com as outras partes que compõem a sociedade (ROSA, 2007). Nesse sentido, os mais variados âmbitos sociais que, por séculos, ignoraram as especificidades das pessoas com deficiências precisam se adequar de modo a incluir a todos.

O paradigma da inclusão enfatiza a igualdade de direitos e oportunidades para todos, incluindo as pessoas com deficiência. É, por meio das instituições de ensino, que se deve combater atitudes discriminatórias, sendo a base para proporcionar o desenvolvimento de uma sociedade em que as pessoas façam parte de forma completa (ROCHA; MIRANDA, 2009). Dessa maneira, a universidade, como instituição plural que deve ser, precisa estar aberta e acessível para receber os mais variados tipos de alunos, proporcionando uma educação que não apenas integre, mas que inclua a todos.

É interessante ressaltar que a discussão relacionada à inclusão desses alunos no Ensino Superior evidencia que esse espaço deixou de ser um lugar inalcançável e elitizado, sendo visto como um lugar possível e de direito a todos que querem ocupá-lo. Parte disso, deve-se à implementação de ações afirmativas que reservam cotas para a inclusão de pessoas que geralmente são marginalizadas em todo o contexto social. Apesar desse avanço, apenas a garantia de entrada não leva a universidade a ser, de fato, inclusiva. Abaixo, isso fica evidenciado no discurso do sujeito coletivo referente a categoria B (Tabela 4). 


\section{Dialogia}

FREITAS, João Paulo Xavier de; OLIVEIRA, Ana Carolina Sales. Discurso do Sujeito Coletivo: a visão dos docentes do curso de ciências biológicas licenciatura de uma Universidade Federal frente à inclusão de alunos com deficiência no Ensino Superior

Tabela 4 - Categoria B: receber conforme a compatibilidade de recursos da Instituição

\begin{tabular}{|l|l|}
\hline \multicolumn{1}{|c|}{ DSC } & \multicolumn{1}{|c|}{ Frequência } \\
\hline É importante verificar a compatibilidade das necessidades do aluno com a & $37,5 \%$ das respostas \\
estrutura e pessoal disponivel na instituição. Nem sempre épossivel atender & compõem este DSC. \\
e apoiar o aluno em sua deficiência. Entretanto, a universidade deve estar & \\
equipada e preparada para receber todos estudantes. & \\
\hline
\end{tabular}

Fonte: Os autores (2019).

É importante evidenciar que é um dever do Estado implementar ações que contribuam não só ao ingresso, mas também que assegurem o percurso dos alunos com deficiência no ensino superior. O DSC aponta que se deve verificar a compatibilidade das especificidades dos alunos com a estrutura da universidade, entretanto, é válido ressaltar que esses estudantes não podem ficar na espera de que a universidade esteja totalmente preparada. Como principal meio de produção de conhecimento científico, ela deve estar sempre à disposição, para que se modifique e, consequentemente, transforme a sociedade. Assim, é necessário ela esteja aberta e que faça intervenções que superem a resistência e os desafios gerados no passado.

\section{O desafio dos docentes frente à entrada de alunos com deficiência na universidade}

Com a finalidade de identificar a percepção dos professores referente aos possíveis desafios que interferem em sua própria prática docente, foi realizada a seguinte pergunta: "você acha que o fato de ter um aluno com deficiência implica ou não em mudanças na sua rotina de trabalho? Se sim, elas são positivas ou negativas?”. Com base nas respostas, foram construídos dois discursos referentes a duas categorias. Na tabela 5, encontra-se o DSC da categoria A.

Tabela 5 - Categoria A: Implica em mudanças positivas

\begin{tabular}{|l|l|}
\hline \multicolumn{1}{|c|}{ DSC } & \multicolumn{1}{|c|}{ Frequência } \\
\hline Sim, positivas. Adaptacões devem ser feitas de acordo com a necessidade. & $50 \%$ das respostas \\
Mesmo em turmas sem alunos com deficiências, adaptações no conteúdo devem & compõem este DSC. \\
ser feitas a fim de otimizar o aprendizado. Elas podem desenvolver as & \\
habilidades didáticas do professor, pois pode obrigá-lo a utilizar outros & \\
recursos além dos tradicionais ou costumeiros. & \\
\hline
\end{tabular}

Fonte: Os autores (2019).

O discurso apontado nessa categoria demonstra que a experiência adquirida por meio da inclusão de alunos com deficiência no Ensino Superior pode potencializar a construção da 
FREITAS, João Paulo Xavier de; OLIVEIRA, Ana Carolina Sales. Discurso do Sujeito Coletivo: a visão dos docentes do curso de ciências biológicas licenciatura de uma Universidade Federal frente à inclusão de alunos com deficiência no Ensino Superior

identidade docente. Tardif (2014) revela que o saber docente está intrinsecamente relacionado ao trabalho em sala de aula, dessa forma, as relações estabelecidas neste ambiente permitem que o professor seja moldado por elas. Assim, para além do uso do saber docente para o trabalho, o professor produz e molda seu saber por meio dele. Tardif $(2014$, p. 8) ainda evidencia que o trabalho docente

trata-se portanto, de um trabalho multidimensional que incorpora elementos relativos à identidade pessoal e profissional do professor à sua situação socioprofissional, ao seu trabalho diário na escola e na sala de aula. (TARDIF, 2014, p. 8).

A inclusão pode proporcionar benefícios para além da descoberta de diferentes estratégias pedagógicas, como citado no DSC. O docente pode aprimorar, por meio dela, o relacionamento interpessoal com seus alunos, a adequação de suas aulas para diferentes turmas, o cuidado com as diferenças e, também, o tato com os materiais didáticos utilizados. É válido ressaltar que o cuidado com os alunos se transforma em um compromisso permanente, sendo o professor responsável por gerar espaços em que haja o desenvolvimento de seus educandos. Entretanto, metade dos professores entrevistados acredita que, para além dos benefícios, a inclusão exigirá uma maior dedicação e trabalho docente. Abaixo (Tabela 6) encontra-se o DSC referente à categoria B desta pergunta.

Tabela 6 - Categoria B: Exige maior dedicação docente

\begin{tabular}{|c|c|}
\hline DSC & Frequência \\
\hline $\begin{array}{l}\text { Acredito que a presença de um aluno com deficiência exige do docente uma } \\
\text { preparação mais adequada e inclusiva de suas aulas, exige uma reflexão constante } \\
\text { no sentido de buscar entender e verificar se realmente esse aluno está sendo incluido } \\
\text { e tendo suas demandas atendidas. Um estudante com deficiência implica em } \\
\text { mudanças profundas no planejamento e no desenvolvimento das atividades. Isso } \\
\text { demanda muito estudo e preparo do docente para que os estudantes com deficiência } \\
\text { tenham acesso ao conteúdo sistematizado e possam ter condiçoes de aprendizagem } \\
\text { adequadas. O ponto negativo seria o mesmo que existe para todas as outras } \\
\text { atividades da universidade: o pouco tempo que o professor universitário dispõe para } \\
\text { se dedicar a todos seus afazeres profissionais, bem como o pouco recurso financeiro } \\
\text { para a adequação dos espaços e dos recursos para o desenvolvimento das atividades } \\
\text { básicas da universidade. }\end{array}$ & $\begin{array}{l}50 \% \text { das respostas } \\
\text { compõem este } \text { DSC. }\end{array}$ \\
\hline
\end{tabular}

Fonte: Os autores (2019). 
FREITAS, João Paulo Xavier de; OLIVEIRA, Ana Carolina Sales. Discurso do Sujeito Coletivo: a visão dos docentes do curso de ciências biológicas licenciatura de uma Universidade Federal frente à inclusão de alunos com deficiência no Ensino Superior

Como apontado no DSC, o contato com esses alunos exige uma prática reflexiva e planejada para que sejam alcançados de maneira efetiva. A necessidade de adquirir saberes em que o docente não pode reinventar sozinho vem ao encontro da importância da reflexão de sua prática, pautada no âmbito das ciências humanas (CASTANHO; FREITAS, 2006). Assim, esse professor necessita de uma preparação sólida, não se restringindo apenas a suas experiências pessoais.

A falta de preparo, de recursos da instituição e de experiências relacionadas à inclusão educacional pode deixar o docente com sobrecarga de trabalho. Isso fica evidenciado no DSC, ainda mais quando se destaca o grande número de atribuições que este profissional possui nas universidades. Dessa forma, é necessário que se crie alternativas que facilitem o seu trabalho, visto que os alunos com deficiência têm direito a receber uma educação de qualidade que promova o desenvolvimento de suas habilidades.

\section{Considerações Finais}

O conceito de inclusão no Brasil e no mundo sofreu alterações consideradas recentes em comparação ao grande caminho de exclusão vivenciado no passado. Nos últimos 30 anos, foi possível criar, no país todo, um aparato legal que modificou esse cenário de segregação, facilitando o ingresso de alunos com deficiência no Ensino Superior. Todavia, nota-se as dificuldades enfrentadas pelas universidades ao incluir esse público alvo, no que concerne à permanência e à entrega de uma formação adequada.

Apenas o ingresso desses alunos não garante a promoção de práticas realmente inclusivas pelas universidades. Entretanto, é válido ressaltar que, como a inclusão educacional perpassa todos os níveis acadêmicos, a universidade acaba possuindo um papel fundamental para a promoção de práticas inclusivas em todo cenário nacional, tendo em vista seu papel na sociedade.

Dessa forma, para que haja uma inclusão educacional de alunos com deficiência no ensino superior eficiente, é necessário, além da readequação estrutural e do uso de tecnologias assistivas, uma flexibilização do currículo acadêmico e a devida preparação dos professores para que atinjam uma prática reflexiva que potencialize o desenvolvimento de seus alunos. Além disso, as possibilidades e as discussões sobre esse assunto devem ser potencializadas, tendo em vista a escassez de trabalhos voltados ao tema.

\section{Referências}

BRASIL. Constituição da República Federativa do Brasil. Brasília: Imprensa Oficial, 1988. 


\section{Dialogia}

FREITAS, João Paulo Xavier de; OLIVEIRA, Ana Carolina Sales. Discurso do Sujeito Coletivo: a visão dos docentes do curso de ciências biológicas licenciatura de uma Universidade Federal frente à inclusão de alunos com deficiência no Ensino Superior

BRASIL. Declaração de Salamanca e linha de ação sobre necessidades educativas especiais. Brasília: UNESCO, 1994.

BRASIL. Lei n. 9.394, de 20 de dezembro de 1996. Estabelece as diretrizes e bases da educação nacional. Diário Oficial da República Federativa do Brasil. Brasília, 23 dez. 1996.

BRASIL. Ministério da Educação/Gabinete do Ministro (GM). Aviso Circular n 277. Brasília: MEC/GM, 1996.

BRASIL. Ministério da Educação. Portaria Ministerial no 1.679/99. Dispõe sobre os requisitos de acessibilidade à pessoa portadora de deficiência para instruir processos de autorização e reconhecimento de cursos e de credenciamentos de instituições. Brasília, 1999.

BRASIL. Decreto no 3.298, de 20 de dezembro de 1999. Presidência da República. Brasília: Paraná, 1999.

BRASIL. Ministério da Educação. Secretaria de Educação Especial. Diretrizes Nacionais para a educação especial na educação básica. Brasília, 2001.

BRASIL. Decreto $\mathrm{n}^{\circ}$ 5.626, de 22 de dezembro de 2005. Dispõe sobre a Língua Brasileira de Sinais - Libras, e o art. 18 da Lei no 10.098, de 19 de dezembro de 2000. Diário Oficial da República Federativa do Brasil. Brasília, 23 dez. 2005.

BRASIL. Ministério da Educação/Secretaria de Educação Especial (SEESP). Política Nacional de Educação Especial na Perspectiva da Educação Inclusiva. Brasília: MEC, 2008.

BRASIL. Lei no 13.146, de 6 de julho de 2015. Institui a Lei Brasileira de Inclusão da Pessoa com Deficiência. Estatuto da Pessoa com Deficiência. Diário Oficial da União, Brasília, 7 jul. 2015.

BRASIL. Resolução CNE/CEB 01, de 18 fev. 2002. Diretrizes Curriculares Nacionais para a Formação de Professores da Educação Básica. 2002. Disponível em: Acesso em: 10 dez. 2019.

CABRAL, Leonardo Santos Amâncio. Inclusão do público-alvo da Educação Especial no Ensino Superior brasileiro: histórico, políticas e práticas. Revista de Educaşão PUC-Campinas, n. 22, p. 371 387, 2017.

CASTANHO, Denise Molon; Freitas, Soraia Napoleão. Inclusão e prática docente no ensino superior. Revista Educação Especial, n. 27, 2006.

FERRARI, Marian A L Dias; SEKKEL, Marie Claire. Educação inclusiva no ensino superior: um novo desafio. Psicologia Ciência e Profissão, v. 27, n. 4, p. 636-647, 2007.

FIGUEIREDO, Marília Z. A.; CHIARI, Brasilia M,; GOULART, Bárbara N. G. de. Discurso do Sujeito Coletivo: uma breve introdução à ferramenta de pesquisa qualiquantitativa. Distúrbios da Comunicação, n. 25, p. 129-136, 2013.

LEFEVRE, Fernando; LEFEVRE, Ana Maria Cavalcanti. O sujeito coletivo que fala. InterfaceComunicação, Saúde, Educação, v. 10, p. 517-524, 2006. 
FREITAS, João Paulo Xavier de; OLIVEIRA, Ana Carolina Sales. Discurso do Sujeito Coletivo: a visão dos docentes do curso de ciências biológicas licenciatura de uma Universidade Federal frente à inclusão de alunos com deficiência no Ensino Superior

LEFEVRE, Fernando; LEFEVRE, Ana Maria Cavalcanti. Discurso do Sujeito Coletivo: Representações sociais e intervenções comunicativas. Texto \& Contexto Enfermagem, v. 23, p. 502507, 2014.

MOREIRA, Laura Ceretta; BOLSANELLO, Maria Augusta; SEGER, Rosangela Gehrke. Ingresso e permanência na Universidade: alunos com deficiências em foco. Educar em Revista, n. 41, p. 125-143, 2011.

ROCHA, Telma Brito; MIRANDA, Theresinha Guimarães. Acesso e permanência do aluno com deficiência na instituição de ensino superior. Revista Educação Especial, v. 22, n. 34, 2009.

ROSA, Ângela Coronel da. Compreendendo o paradigma da inclusão. Revista Educação Especial, n. 29, 2007.

SANT'ANA, Izabella Mendes. Educação Inclusiva: concepções de professores e diretores.

Psicologia em estudo, n. 10, 2005.

TARDIF, Maurice. Saberes docentes e formação profissional. Rio de Janeiro, Editora Vozes Limitada, 2012.

UNESCO. Declaração Mundial sobre Educação para Todos: plano de ação para satisfazer as necessidades básicas de aprendizagem. Tailândia, 1990.

Recebido em: 24 mar. 2020/ Aprovado em: 06 jul. 2020

\section{Cite como}

\section{(ABNT NBR 6023:2018)}

FREITAS, João Paulo Xavier de; OLIVEIRA, Ana Carolina Sales. Discurso do Sujeito Coletivo: a visão dos docentes do curso de ciências biológicas licenciatura de uma Universidade Federal frente à inclusão de alunos com deficiência no Ensino Superior. Dialogia, São Paulo, n. 35, p. 6478, maio/ago. 2020. Disponível em: https://doi.org/10.5585/dialogia.n35.16869.

\section{American Psychological Association (APA)}

Freitas, J. P. X., \& Oliveria, A. C. Sales (2020, maio/ago.). Discurso do Sujeito Coletivo: a visão dos docentes do curso de ciências biológicas licenciatura de uma Universidade Federal frente à inclusão de alunos com deficiência no Ensino Superior. Dialogia, São Paulo, 35, p. 64-78.

https://doi.org/10.5585/dialogia.n35.16869. 